\title{
EL TRANSPORTE DE ESCLAVOS MUSULMANES A TRAVÉS DE VALENCIA EN LOS PRIMEROS AÑOS DEL REINADO DE ALFONSO EL MAGNÁNIMO, 1421-1440 *
}

POr
PAUL PADILLA

A pesar de toda su repugnancia a la sensibilidad moderna, la esclavitud continuó siendo una costumbre corriente durante la mayor parte de la historia escrita (1). El transporte de esclavos continuó ininterrumpido en la Europa mediterránea durante toda la Edad Media y buena parte del período moderno. En muchas ciudades portuarias del Mediterráneo la compra, venta y transporte de esclavos constituyó un porcentaje del comercio de una ciudad, y en cuanto a esto Valencia no se diferenciaba de sus ciudades portuarias gemelas. Durante todo el siglo XV, Valencia continuó siendo una de las ciudades más prósperas de la Corona de Aragón, incluso de algún modo suplantando a Barcelona como la capital financiera. Al examinar las relaciones del Maestre Racional referentes al transporte de esclavos a través del Reino de Valencia durante los primeros años del reinado de Alfonso el Magnánimo, el presente trabajo busca sentar las bases para un estudio preliminar sobre la esclavitud en la Valencia de principios del siglo $X V, y$ de ese modo añadir nuevos datos a nuestro conocimiento del comercio de esclavos en el mundo mediterráneo (2).

- Una primera versión de este ensayo fue leida en el 22 nd International Congress on Medieval Studies en Kalamazoo, Michigan, el 8 de Mayo de 1987. Quisiera expresar mi gratitud a los profesores Mary Elizabeth Perry y Robert I. Burns, S. J. que leyeron e hicieron el proyecto en su primera fase. A todos ellos mi más sincero agradecimiento por sus atenciones y generosidad.

(1) DAVID BRION DAVIS, The Problem of Slavery in Western Culture (Ithaca 1966). Constituye la introducción usual al tema de la esclavitud en la sociedad occidental; véase también su Slavery and Human Progress (Oxford 1984). Más recientemente, WILLIAM D. PHILLIPS, Slavery from Roman Times to the Early Transatlantic Trade (Minneapolis 1985), proporciona una excelente síntesis de obras sobre el tema. JACQUES HEERS, Esclaves et domestics au Moyen-Age dans le monde méditerranéen (París 1981) analiza la esclavitud mediterránea en el período fines de laEdad Media-Renacimiento.

(2) El cuadro que presento es fragmentario debido a la escasez de documentación. Estamos mejor provistos para el período posterior gracias a Vicenta Cortés Alonso, La esclavitud en Valencia durante el reinado de los Reyes Católicos (Valencia 1964). VICENTE GRALLERA SANZ, La esclavitud en Valencia en los siglos XVI y XVII (Valencia 1978), y HENRY KAMEN, aMediterranean Slavery in its Last Phase: the case of Valencia 1660-1700" Anuario de historia económica y social 4 (1970), pp. 211-234. 
Una amplia diversidad de procedencias para el suministro de esclavos existió en la España medieval y del Renacimiento. Éstas incluían la conquista militar, la piratería y el corso, incursiones o expediciones de forrajeo, y por supuesto, el comercio de esclavos. La esclavitud podia también derivarse del nacimiento; casamiento; castigo de una ofensa o crimen (servus poenae); como resultado de deuda (obnoxiatol; o por aceptar voluntariamente la esclavitud (3). Marc Bloch ha indicado que en la mayor parte de la Europa Occidental la esclavitud se transformó en otras formas de servidumbre, pero en aquellas zonas fronterizas de la Europa católica (por ejemplo, las tierras reconquistadas a los musulmanes o las áreas marginales de la Europa oriental) continuó habiendo un suministro constante de esclavos potenciales (4). Tal era el caso en Valencia. Debido a su proximidad geográfica a la costa mediterránea y a la frontera musulmana, las dos principales procedencias de la esclavitud en Valencia continuaron siendo el comercio de esclavos, y los cautivos obtenidos mediante incursiones de corso, los cuales eran más tarde vendidos como esclavos.

Tanto el Islam como el cristianismo hicieron su aparición en la historia en sociedades donde la esclavitud era una costumbre social y económica ya aceptada, y así había de continuar en ambas religiones. No sería sino hasta el periodo moderno cuando las actitudes religiosas hacia este estado servil serían drásticamente alteradas. A lo largo del siglo XV, la lucha entre el Islam y los reinos cristianos de la península lbérica continuó poco más o menos como antes. Estas hostilidades - tanto como campañas militares formales, incursiones de corso, o simple piratería -- proporcionaron un flujo continuo de esclavos para ambas partes. Los piratas musulmanes y cristianos y los corsarios atacaban la flota del contrario, y los cautivos eran vendidos en los mercados de esclavos a menos que pudieran ser rescatados. En lo que respecta a los cristianos, esto dio lugar a órdenes de rescate como los Mercedarios y los Trinitarios (5).

(3) CHARLES VERLIND en, L'esclavage dans I'Europe médiévale, Tome premier: Pénimsule ibérique-France (Bruges 1955), l: pp. 62-79 y I: pp. 251-278; asimismo Leopoldo Piles Ros, Apuntes para la historia económica social de Valencia durante el siglo XV (Valencia 1969), 162. John Boswell ha demostrado que los musulmanes incapaces de identificar a su señor o dueño, o que hubieran violado leyes y códigos de vestuario podían verse sometidos a esclavitud. The Royal Treasure, Muslim Communities under the Crown of Aragon in the Fourteenth Century (New Haven 1977), pp. 50-51 y 346-347.

(4) Véase su "How Slavery Came to an End", en Slavery and Serfdom in the Middle Ages, Selected Papers by Marc Bloch (Berkeley y Los Angeles 1975l, pp. 29-30, y "Mediaeval "Inventions" en Land and Work in Medieval Europe, Selected Papers by Marc Bloch (Berkeley y Los Angeles 1967), pp. 179-180.

(5) Sobre las antiguas ódenes de rescate en Valencia véase el cap. 13 de ROBERT I. BURNS. S. J. The Crusader Kingdom of Valencia: Reconstruction on a Thirteenth-Century Frontier, 2 vols. (Cambridge, Mass. 1967). Revisado como EI Reino de Valencia en el siglo XIII, (Valencia 1982). JAMES WILLIAM BRODMAN Ransoming Captives in Crusader Spain. The Order of Merced on the Christian-Islamic Frontier (Filadelfia 1986) proporciona un estudio de los Mercedarios en la Edad Media tardia. En cuanto a los siglos XVI y XVII véase a ELLEN G. FRIEDMAN. Spanish Captives in North Africa in the Early Modern Age (Wisconsin 1983). Sobre los esfuerzos de musulmanes y cristianos para el rescate de cautivos véase a JUAN TORRES FONTES, "La Hermandad de moros y cristianos para elrescate de cautivos", I Simposio Internacional de Mudejarismo (Madrid-Teruel 1981), pp. 499-508, y MARÍA TERESA FERRER MALLOL, "La redemció de captius a la Corona catalano-aragonesa (segle XIV)", Anuario de estudios medievales 5 (1985), op. 237-298. 
Algunas regiones del mediterráneo tenían sus propias características singulares y exclusivas relativas a la esclavitud. En el Levante encontramos ese fenómeno musulmán único y exclusivo del esclavo militar mam/ūk, un individuo que es un esclavo adquirido, pero entrenado para el servicio militar como soldado profesional (6). Esta poderosa élite militar con el tiempo se convirtió en gobernante de Egipto desde 1250 a 1517 . El estudio de la esclavitud en el África islámica también ha atraído recientemente una merecida atención (7). Pero en su mayor parte la esclavitud en el mundo mediterráneo continuó siendo un fenómeno urbano, y se tendía a utilizar a los esclavos como domésticos $y$ artesanos. Hallamos que hacia el final del siglo XIV en Italia, por ejemplo, estaba bastante de moda el que una familia acaudalada tuviera al menos un esclavo de tal tipo (8). Podemos generalizar la esclavitud mediterránea como sigue: era ante todo un fenómeno urbano; el esclavo realizaba principalmente trabajo doméstico o servicio personal, y los esclavos varones eran empleados por lo general en puestos de confianza. Es importante, además, tener presente que la posesión de un esclavo era contemplada com un lujo (9). La adquisición de un esclavo suponía una inversión considerable por parte del comprador. En el occidente cristiano se consideraba a los esclavos como propiedad esencialmente, como mercaderías que podían ser compradas, vendidas, heredadas, o legadas como dote. También en el Islam encontramos que los esclavos estaban generalmente sujetos a la discreción de sus dueños; pero también hallamos esclavos implicados en litigios en los tribunales musulmanes, así como otorgando su consentimiento en el asunto de su propia venta (10). Deberíamos tener presente que los esclavos conservaron ciertos derechos humanos bajo la ley islámica.

Dos documentos de fines del siglo XIV de Jerusalén ilustran cómo habian de intervenir los tribunales musulmanes en el trato esclavo-amo cuando se cuestionaba la competencia legal del amo (11). En el primero de ellos, fechado el 10 de octubre de 1391, los huérfanos de Maqarr Badr al-Dín deseaban vender las cuatro muchachas esclavas, el mamlük Balabān, y un mulo que habian heredado. El tribunal convino en «que los huérfanos debían ser

(6) Sobre los Mamluks véase a David Ayalon, Studies of the Mamlüks of Egypt Society: Collected Studies (London 1977). y The Mamluk Military Society: Collected Studies (London 1979); también a DONALD P. LITTLE, History and Historiography of the Mamluks (London 1986). PATRICIA CRONE, Slaves on Horses, The Evolution of the Islamic Polity (Cambridge 1980), y DANIEL PIPES, Slaves, Soldiers and Islam. The Genesis of a Military System (New Haven 1981), también son estudios valiosos sobre la antigua esclavitud militar.

(7) Puede encontrarse un buen sumario en DAVIS, Slavery and Human Progress, cap. 4; asimismo, JOHAN RALPH WILLIS, ed. Slaves and Slavery in Muslim Africa, 2 vols. (London 1985); véase especialmente el volume 1: Islam and the ldeology of Enslavement.

(8) JOHN LARNER, Italy in the Age of Dante and Petrarch, 1216-1380. (London 1980), p. 199.

(9) ROBERT S. LOPEZ E IRVING W. RAYMOND, eds. Medieval Trade in the Mediterranean World (New York 1955), 115, S. D. GOITEIN, A Mediterranean Society: The Jewish Communities of the Arab World as Portrayed in the Documents of the Cairo Geniza, 4 vols. hasta ahora. (Berkeley y Los Angeles 1967 sigs.), 1: pp. 130-147. ROBERT 1. BURNS. S. J., Islam under the Crusaders: Colonial Survival in the Thirteenth-Century Kingdom of Valencia (Princeton 1973), pp. 109-113

(10) LÓPEZ, p. 116; Goitein, 1: pp. 141-142.

(11) DONALD P. LITTLE, "Two Forteenth-Century Court Records from Jerusalem Concerning the Disposition of Slaves by Minors", Arabica 27 (1982), pp. 16-49. 
librados de la necesidad de mantener a éstos ellos mismos, y que el no venderlos perjudicaría a los huérfanos arriba mencionados e impondría una carga sobre ellos" (12). En otro documento (5-14 de diciembre de 1394), cuatro esclavos -al-Maqqadam, Mubārak, Mubāraka, e Inshirāh- se presentaron ante el tribunal para sostener que su difunto amo Muhibb al-Din les había garantizado la libertad justo antes de morir. El tribunal escuchó su caso y determinó que el menor de edad "había alcanzado la pubertad, pero que permanecía bajo impedimento legal» porque todavía no había llegado a «la edad de discernimienton (13). Por lo tanto todos los esclavos fueron vendidos a excepción de Mubārak, quien, temeroso del destino que le amenazaba, huyó a Damasco. Dado que los esclavos no eran personas adultas ante la ley en los tribunales islámicos, así también en Valencia los esclavos se beneficiaban de la protección de la ley pero carecían de ciertos derechos civiles. Los Furs de València, aquel extenso código jurídico que Jaume el Conqueridor promulgó para su reino recién conquistado, situaba a los esclavos bajo la categoría de disciplina doméstica junto con los menores de edad, las mujeres, y los incapaces mentales (14).

La cuestión de la conversión es es un asunto muy espinoso y complicado. Teóricamente, los musulmanes y los judíos podían poseer infieles y cristianos como esclavos en los países islámicos, pero no a otros musulmanes. Si un esclavo se convertía, se le exigía que se convirtiera al Islam y técnicamente ya no sería esclavo. Durante la Edad Media los cristianos podían poseer musulmanes y paganos como esclavos, pero no deberían poseer otros cristianos. Sin embargo, la conversión al cristianismo no era necesariamente un camino para la manumisión. Los Padres de la Iglesia ya habían afirmado que el bautismo no afectaba a la condición social de un esclavo, y la esclavitud era una institución perfectamente aceptable en la cristiandad medieval. En el Reino Latino cruzado los esclavos eran musulmanes, judíos y cristianos orientales (15). De un modo parecido, encontramos en la Europa católica que en los esclavos se había de incluir no sólo a paganos y musulmanes, sino también a aquellos cristianos considerados heréticos y cismáticos. Cuando se introdujo a los esclavos en la Europa occidental, en algunos países (Italia por ejemplo) se hizo un esfuerzo para convertirlos al cristianismo, pero en España no se emprendió tal esfuerzo de conversión (16). Más aún, los católicos podían ser esclavizados como castigo de una ofensa criminal, o como resultado de hostilidades militares. Durante el reinado de Pedro el Ceremonioso encontramos muchos ejemplos de esclavos cristianos sardos, la mayoría producto de la subyugación y pacificación de Cerdeña por parte de Pedro, que eran

\footnotetext{
(12) Ibid., p. 21

(13) bid., pp. $31-33$.

(14) Fori antigui Valentiae, MANUEL DUALDE SERRANO, ed. (Madrid-Valencia 1950-1967), rub. 83, no 9: aDomesticos vocamus uxores, servos, liberos mercannarios, nepotes, discipulos, scolares, et omnes mares et feminas qui sint de familian; BURNS, islam, op. cit.

(15) JOSHUA PRAWER, Crusader Institutions (Oxford 1980), p. 208

(16) Heers, pp. 95-108.
} 
vendidos y llevados a ciudades a lo largo y ancho de la Corona de Aragón (17). Al principio del Renacimiento hallamos fuerte desaprobación ante la esclavitud de hombres y mujeres de cualquier tierra cristiana. Florencia, en su autorización formal del comercio de esclavos de 1363, estipuló que se importara únicamente a los no cristianos. Una bula papal de 1425 amenazaba a los mercaderes de esclavos cristianos con la excomunión (18).

La esclavitud estaba omnipresente en la federada Corona de Aragón, y en el Reino de Valencia en particular. Los catalanes consideraron innecesario esclavizar de una manera activa a los judíos o cristianos orientales, por la abundante provisión de cautivos musulmanes disponibles. Poco esfuerzo se destinó a la conversión activa de musulmanes esclavizados. Los cautivos musulmanes, ya fueran provenientes del norte de África, ya del Reino de Granada, no eran bautizados y continuaban usando sus nombres árabes. A estos esclavos musulmanes así como a sus equivalentes mudéjares - la población indígena de la España musulmana - se les llamaba al principio "sarracenos" /sarrains o sarrahins), pero con el tiempo fueron llamados por sus contemporáneos "moros", aunque en latín oficial y en documentos en lenguas vernáculas todavía se les refiere en ocasiones como «sarracenos». La principal fuente de esclavos en nuestra documentación la constituía los cautivos obtenidos por los piratas y corsarios. Encontramos por consiguiente que términos como ucautivo" (catiu), "siervo" (servu), y "esclavo" (sclau) eran sinónimos en los Furs, $y$ con frecuencia se usan indistintamente al referirse a esclavos musulmanes (19)

Pero una vez esclavizados, los cautivos musulmanes no eran relegados necesariamente a una posición social permanente. Estos musulmanes podían ganarse su libertad, podían ser rescatados mediante limosnas musulmanas, o podían ser liberados como un último acto piadoso en el testamento de su amo. Al obtener su libertad podían regresar a su hogar, pero probablemente un buen número de ellos se asimiló a la comunidad mudéjar local. La situación en Valencia no favorecía el proselitismo religioso. La proximidad relativa a otros estados musulmanes, la existencia de una considerable comunidad mudéjar, unido a la fuerza y consuelo que recibían de su religión, proporcionaban al cautivo musulmán la esperanza (siquiera remota) de regresar a su tierra natal (20). Sin embargo se daban conversiones. En 1304 Jaime Pons consintió en vender su esclava musulmana Fátima a un grupo de musulmanes, aunque su conversión al cristianismo invalidó el contrato. Pons fue obligado a devolver el dinero, y Fátima quedó como persona libre. Más aún, los

(17) JOHANNES VINCKE, HKönigtum und Sklaverei im aragonischen Staatenbund während des 14. Jahrhundrets", Gesammelte Aufsatge zur Kulturgeschichte Spaniens 25 (197?), pp. 19-112; EVANDRO PUTZULU, «Schivari sardi a Maiorca nella seconda metà del secolo XIV". VI Congreso de historia de la Corona de Aragón (Madrid 1959), pp. 365-378; y JOSEP MARIA MAUDRELL MARIMON, "Vend es d'esclaus sards de guerra a Barcelona en 1374\%, VI CHCA, pp. 285-289.

(18) LARNER, p. 200; DAVIS, The Problem of Slavery. pp. 98-99. PIERO GUARDUCCI Y VALERIA OTTANELLI, I servitori della casa Borghese Toscana nel basso medioevo (Firenze 1982)

(19) ROQUE CHABÁS y LLORÉNS (ed.), "La esclavitud en Valencia", El Archivo, 4 (1890), p. 267.

(20) Heers, pp. 90-99 
conversos musulmanes resultaron inestimables en el rescate de cautivos cristianos. El 10 de marzo de 1423 el consejo municipal de Valencia pagó a Juan de Bordils, un musulmán convertido al cristianismo. veinte florines de oro por sus servicios en la liberación de dieciséis cautivos cristianos en Almería (21).

A medida que los esclavos eran transportados a través del Reino de Valencia y los barcos atracaban en el puerto de la ciudad de Valencia, al propietario o capitán del barco se le requería el pago de unos derechos por el transporte del esclavo (dret de passatge) al Maestre Racional, el principal funcionario fiscal del Reino de Valencia. Si los cautivos eran botín de guerra, a aquéllos se les requería además el entregar al rey su parte legítima en la captura del botín (lo dret al Senyor Rey). La costumbre había establecido la suma a un quinto del valor del botín obtenido. El Maestre Racional había de registrar el número de esclavos/cautivos transportados además de hacer una lista del dinero recibido. En ocasiones se nos da los nombres de los cautivos, su sexo, o si son o no de raza negra. Algunas veces se nos proporciona su lugar de origen y destino. Nuestra documentación es en cierto modo fortuita e irregular; ciertamente es incompleta. Sin duda alguna hubo contrabando, pero en qué medida es difícil decirlo, dado que la única documentación que poseemos acerca de tales actividades ilícitas sólo tiene que ver con aquellos malogrados individuos que fueron detenidos. Otros funcionarios reales y municipales tenían también jurisdicción y mencionan a musulmanes en sus respectivos documentos. El presente estudio, con todo, nos permite vislumbrar el comercio de esclavos de Valencia.

Mientras que algunos de los esclavos relacionados resultan del tráfico de esclavos, hallamos que la mayoría son cautivos obtenidos como botín durante un perfodo de abiertas hostilidades (de bona guerra) con las potencias musulmanas vecinas. Ahora bien, efectivamente la línea divisoria entre piratería y corso no está claramente delimitada. Un corsario recibía una comisión -o directamente mediante una carta formal o patente, o implícita si existían hostilidades abiertas entre la Corona de Aragón y una potencia vecina cristiana o musulmana - para atacar el comercio de un enemigo, y lo capturado a estos navíos constituía presa de guerra. Encontramos en aquel famoso código judicial marítimo catalán, el Llibre del Consolat de Mar, que los corsarios están en su derecho cuando atacan a la flota enemiga (22). Crimen cometido de manera altruista, ¿qué puede ser más gratificante para un pirata? Cuando cesaban las hostilidades se contaba con que el corsario desistiera de nuevos

(21) MIGUEL GUAL CAMARENA, "Mudéjares valencianos, aportaciones para su estudio", Saitabi 7 i 19491 р. 169

(22) FERRERI MALLOL, p. 241. Llibre del Consolat de Mar, 2 vols. Germà Colon i Arcadi Garcia ed. (BarceIona 1981 y 19821. cap. 276: "Si alcuna nau o leny armat qui entrarà encors o n'exirà o'y serà s'encon trarà ab alcuna altra nau o leny de mercaderia, si aquela nau o aquell leny armat pendrà aquela nau o aquell leny e la mercaderia serà de anamics e so que ons serà, en assò no cal àls dir. Per què? Per so car casun és tant sert què ja sap que n'à a ffer, perquè no cal en aytal cas posar alcuna rahón. Véase además el clásico estudio de Antonio de Capmany y de Monpalau, Memorias históricas sobre la marina comercio y artes de la antigua ciudad de Barcelona, 3 vols. ed. rev. E. GIRALT y RAVENTÓS Y C. BATLLE GALLART (Barcelona 1961-1963). Un reciente estudio sobre la piratería catalana y el corso es la monografía de ANNA UNALI, Marinai, pirati e corsari catalani nel basso medioevo (Bologna 1983) 
ataques a la flota del enemigo. Si no lo hacía así, era entonces considerado un pirata, y como tal estaba sujeto a procesamiento criminal si era apresado por las autoridades (23).

Nuestros primeros datos se dan en el año 1421. En los registros del Maestre Racional constan dieciocho esclavos y cautivos. Tres de ellos son mujeres, seis constan concretamente como esclavos, y el resto como cautivos; de los últimos se registra a cuatro como botín de guerra, y se les lleva a todos ellos en el navio de Joan de Cordova. Su barco es de la ciudad de Cartagena, y podemos asumir con toda seguridad que estos cautivos eran del Reino de Granada. Siete de estos cautivos son de raza negra; a diez de los dieciocho se les dirige a Barcelona, uno es destinado a Mallorca, y no poseemos datos de los siete restantes (24).

En lo que respecta al año siguiente de 1422, encontramos que se reciben dieciocho cautivos musulmanes en el puerto de Valencia. Sólo uno de ellos era mujer, ninguno de raza negra, y todos ellos botines de guerra. El 2 de marzo se registra a García Ruiz, capitán de un navío armado de Cartagena, como portador de una mujer y siete varones cautivos musulmanes (25). El 16 de junio se registra a Berthomeu Silvestre como portador en su navío armado de Cullera, de dos musulmanes capturados (26). En el mes siguiente (22 de julio). Berenguer Armengol hace entrar a cuatro cautivos a la ciudad de Valencia (27), y al día siguiente de nuevo hallamos a nuestro conocido Joan de Cordova haciendo entrar a cuatro cautivos musulmanes adicionales (28). Sólo tenemos un registro en 1423: a poco de comenzar el año Martí Uira desembarca nueve cautivos musulmanes en el puerto de Valencia en su navío corsario armado (29).

Nuestra documentación enmudece en este punto hasta junio de 1430, donde encontramos un controvérsico episodio implicando a cautivos musulmanes. El registro es de una longitud extraordinaria, tres folios completos;

(23) Para un estudio del tema de los corsarios-piratas en la Valencia del siglo XIII véase el cap. 4 de ROBERT 1. BURNS, S. J., Muslims, Christians, and Jews in the Crusader Kingdom of Valencia (Cambridge 1984)

(24) Véase el apéndice.

(25) Archivo del Reino de Valencia, Maestre Racional, Reg. 42, fol. 86 v: (2 de marzo de 1422) "reebe per mi lo dit en Daniel Barcelo d'en Garcia Roiz de un llaut o barqua armada dela ciutat de Gartagenia per mans d'en Arnau Font mercad er per lo dret al senyor Rey pertanyent de vi moros e una mora que li aitugi de bona guerran.

(26) A. R. V., Maestre Racional, Reg. 42, fol. 86v: (16 de junio de 1422) «reebe per mi lo dit en Danie Barçelo d'en Berthomeu Silvstre patro de un leny armat de xviiii rems dela vila de Culiera per lo dret al senyor Rey pertanyent de ii moros que li aiutgi de bona guerran.

(27) A, R. V., Maestre Racional, Reg. 42, fol. 87: (22 de julio de 1422) «d'en Berenguer Armengol patro de una barqua armada per mans de Fferrando Guillem scriva dela dita barqua per quatre moros que li aiutgi de bona guerra».

(28) A. R. V., Maestre Racional, Reg. 42, fol. 87: (23 de julio de 1422) «d'en Johan de Cordova patro de barqua armada de Cartagenia per lo dret al senyor Rey pertanyent quatre moros que li aiugti de bona guerra".

(29) A. R. V., Maestre Racional, Reg. 43, fol. 93: (? de febrero de 1423) «ltem pos en data d'en Marti de uira patro de un leny armat per mans de Johan de Cordena mariner per lo dret al senyor Rey pertanyent per viiii testes de moros que per mi lo son estats aiutgats de bona guerran. 
harto insólito para unos registros fiscales caracterizados por su brevedad $y$ concisión (30). Vasco Andrea, un mercader portugués, que actúa como portavoz de un grupo de mercaderes y capitanes de navío, trae cinco cautivos del Reino de Fez, los cuales sostiene que son legítimo botín de guerra. El Maestre Racional se ha puesto de acuerdo evidentemente con Vasco Andrea sobre una cantidad fija, ya fuera en cautivos o en botín, que éste tenía derecho a recibir (quizá como indemnización o como una compensación). En cualquier caso, surgió una discrepancia entre ambas partes y el Maestre Racional, obrando en nombre del interés real, hace entregar a los cautivos a su oficial a cargo del suburbio del puerto de Valencia hasta que el asunto se resuelva. La disputa entre las dos partes continúa durante varios días, y un grupo de «individuos notables» entran en la discusión para hacer de mediadores en el asunto. El desacuerdo se centra en la suma de botín que el rey tiene derecho a recibir, y la suma que le había sido prometida a Vasco Andrea. La decisión final fue que cada parte recibiría dos cautivos y medio, y Vasco Andrea recibiría la suma prometida de la porción del Maestre Racional (31).

En 1432 hallamos dos incidentes referentes a cautivos musulmanes traídos a Valencia, $y$ en cada caso se registra a todos los musulmanes como botín de guerra. El 1 de octubre Joan de Rucaffa trae nueve musulmanes (32), y el 27 de noviembre Joan Sant Luçar trae dos cautivos (33). En cada caso se describe a sus barcos como navíos armados, y por ello debían de regresar de incursiones corsarias. Dos años más tarde Joan Lorenç, un capitán de navío portugués, trae a doce musulmanes, de nuevo como botín (34). En 1439 se registra a Pere Busot entregando al rey su parte de botín en una incursión corsaria contra los musulmanes de la costa de Berbería. En esta empresa no se consiguieron cautivos, pero la expedición de Pere Busot sí que logró obtener algunos valiosos bienes (35).

(30) A. R. V., Maestre Racional, Reg. 49, fols. 126v-127v: (12 de junio de 1430)

(31) A. R. V., Maestre Racional, Reg. 49, fol. 127rv: aEt com lo dit en Vasco Andrea me notificas com per lo dit patro dela nau Viana e altres nauis de Portogal fossen preses e cativats cinch moros del realms de Ffez e aquelles tengessen occilcament en la dita nau sens manifestar me aquelles de fet yotramis an Marti Tolsa notari lochiment meu al Grau dela mar de Valencia... Lestret de Gibaltor e en aquelis no haber petanyer dret al cal senyor Rey e on dret alculin pertangues eren prestes de pagar ho yo allegant lo contrari çoes que als dits patrons no pertanya dret algu en los dits moros ans aquelles pertanyer de bona guerra al dit senyor Rey per moltes rahones per aquesta debat e altercacio dura per molts dies entre mi e los dits patrons e mercaders. Entreuents algunes notables persones fon concordat e avegut que los dits cinch moros fossen partits per equals parts entre mi e los dits patrons coes que de aquelles hagues la megtat lo senyor Rey. Et laitra meytat los dits patrons dels quals vench apart del dit senyor Rey hamet galip e Caat mon banich e la meytat per Indius de Amar benabdulcarim. Et com per part del dit en Vasco Andrea me fos demanat lo terc dels dits dos moros e mig..."

(32) A. R. V., Maestre Racional, Reg. 51, fol 67: (1 de octubre de 1432) "d'en Johan de Rucaffa patro de un llaut armat per mans d'en Johan Ramayo per lo dret al senyor Rey pertanyent de Nou testes de moros que li aiugti de bona guerra com pertant se avengues ab mim.

(33) A. R. V., Maestre Racional, Reg. 51, fol. 67: (27 de noviembre de 1432) "d'en Johan de Sent lucar patro de un llaut armat per lod ret al senyor Rey pertanyent de dos moratells que li aiutgi de bona guerra com pertanyent se avengues ab mis.

(34) A. R. V., Maestre Racional, Reg. 52, fol. 82: (15 de noviembre de 1434) «d'en Johan lorenc de Potogal patro de un balener per lo dret al senyor Rey pertanyent per raho de dotze moros que per mi foren aiugats de bona guerra com pertant se avengues ab mi».

(35) A. R. V., Maestre Racional, Reg. 54, fol. 74: (14 de noviembre de 1439) «Pere busot mariner de Valencia per mans d'en Nicholau Vallanra per lo dret del quint al senyor Rey pertanyent contant al $15^{e}$ per de aquelles cix lliuras $x$ sous procehides preu de un caro morish e cert for e altres robes preses per to dit Pere Busot de moros de barberia ab una barqua sua armadan. 
Tenemos algunos registros en 1440, pero bástenos con tres ejemplos. En el primero (fechado el 5 de febrero), Pedro de Jerez presenta seis musulmanes, da al rey su parte correspondiente, y los seis son vendidos por consiguiente en la ciudad de Valencia (36). En segundo lugar (1 de abril), Pere de la Torre entrega al rey su parte en los tres musulmanes capturados como botín, y recibe permiso de venta de los tres cautivos (37). Finalmente, Jaume Scheve y Joan de Lorca entregan al rey lo correspondiente de su botín obtenido en una incursión corsaria, que incluía a dos cautivos musulmanes (38).

Quizás sea importante decir unas palabras sobre el origen étnico de la esclavitud. Aunque indiviuos de raza negra se encuentran sin lugar a dudas en los documentos, la esclavitud mediterránea era principalmente un asunto de religión y tenía poco que ver directamente con la raza; los musulmanes esclavizaban a los cristianos y viceversa. La población negra de África comienza a aparecer en grandes cantidades en Europa en el transcurso del siglo XIV. La palabra "esclavo" en sí y sus varios afines occidentales (slave, schiavo, sklave, etc.) se deriva de aquel grupo étnico que constituyó el más numeroso grupo exterior en el comercio de esclavos mediterráneo, los eslavos. Los esclavos blancos eran asimismo conocidos en el Islam colectivamente como saqāliba (la forma plural de saqalabi, "eslavo») (39). Esta fuente para la provisión de esclavos con el tiempo se cerró a los europeos a! irse convirtiendo estos territorios paganos al cristianismo (40).

Se suponía que los esclavos habían de ser sólo no cristianos, pero el comercio de esclavos era un negocio lucrativo, y dondequiera que se pueda sacar ganancia siempre podremos encontrar individuos emprendedores. Los principales de éstos eran los mercaderes italianos, especialmente los venecianos y genoveses, que eran los mercaderes de esclavos par excellence (41). A pe-

(36) A. R. V., Maestre Racional, Reg. 56, fol. 89: ( 5 de febrero de 1440) "de Pedro de Xerez mariner per lo dret del quint al senyor Rev pertanyent e feta de aquell alquinze per raho de vi moros presentats a mi per aquell venuts en la ciutat de Valencian.

(37) A. R. V., Maestre Racional, Reg. 56, fol. 89: (1 de abril de 1440) «Pere dela Torre mariner per lo dret de quint al senvor Rey pertanyent comptant alquinze en aquelle lxxxvii lliuras per les quals ha venuts tres moros. E dels quals per mi li fon donada e atorgada licencia quals posques vendre".

(38) A. R. V., Maestre Racional, Reg. 56, fol. 93: (25 de agosto de 1440) "d'en Jacme Scheve e d'en Johan de lorqua patrons de fustes armades per lo dret quint al senyor Rey pertanyent comptant alquinze feta gracia a aquelles per raho he aquelfes de dos moros e certa seda e alcarahuya que per mi los es stat aiutgat de bona guerran.

(39) CHARLES VERLINDEN, "L'origin de Sclavus-Esclave» Bulletin Ducagne: Archivum Latinatis Medii Aevi 17 19421, 37-128; BERNARD LEWIS, The Muslims Discovery of Europe (New York 1982), pp. 187$189 ;$ y G. E. VON GRUNEBAUM (trad. Katherine Watson), Classical Islam, A History 600-1258 (London 1970), p. 101. Un extenso artículo sobre la palabra «esclavon en árabe ( $\left.{ }^{\circ} a b d\right)$, puede encontrarse en la Encyclopaedia of Isiam, segunda ed. (Leiden 1960). 1: pp. 24-40.

(40) A. TEIXEIRA DA MOTA, «Entrée d’esclaves noirs à Valence (1445-1482): La replacement de la voie saharienne par la voie Atlantique", evue française d"histoire d'outre mer 66 (1979), pp. 195-210: VICENTA CORTÉS ALONSO, "Procedencia de los esclavos negros en Valencia (1482-1516), Revista española de Antropología Americana, 7 (1972), pp. 123-151; P. E. H. HAIR, "Black African Slaves at Valencia, 1482-1516: An Onamastic Inquirym, Hisfory of Africa: A Journal of Method 7 (1980). pp. 119-139; y MIGUEL GUAL CAMARENA, aUna cofradía de negros libertos en el siglo XV", Estudios de edad media de la Corona de Aragón 5 11952\}, pp. 457-466.

(41) El mejor estudio sobre el papel de los italianos en el tráfico de esciavos en aquel escrito par el decano de la especialidad, CHARLES VARLINDEN, L'esclavage dans I'Europe médievale. Tome deux: Italie-Colonies italiennes de Levant-Levant latim-Empire byzantin (Ghent 1977); véase también C. VERLINDEN (trad. al ing. YVONNE TRECCERO), "Some Aspects 
sar de las prohibiciones de exportación y venta de cristianos a musulmanes, hay muchos casos de esclavistas europeos envueltos en tales transacciones. Ésta era a fin de cuentas una empresa de negocios, y lo que Ibn Jaldūn escribió en el siglo XIV sonaba verídico para: el cristiano como lo era para el dueño musulmán:

\begin{abstract}
Debería ser cosa sabida que el comercio viene a ser el intento de conseguir un beneficio mediante el aumento de capital, a través de la compra de bienes a bajo precio y vendiéndolos a precio mayor, consistiendo estos bienes en esclavos, grano, animales, armas o pañería. A la cantidad acumulada se le llama "beneficio" [ribh] (42).
\end{abstract}

Pero al estudiar el comercio de esclavos el historiador debe tener el cuidado de no empantanarse en los hallazgos estadísticos de sus investigaciones. Charles Dufourcq ha anotado en su estudio magistral sobre las relaciones entre África del norte y la Corona de Aragón que este tráfico comercial de esclavos era, más que cualquier otra cosa, tráfico humano. Así como hubo grandes desplazamientos de población a través del Atlántico hacia el Nuevo Mundo a principios de la Edad Moderna, así también hubo en el Mediterráneo un desplazamiento de población como resultado del comercio de esclavos. De todos modos, esta circulación de población en el Mediterráneo fue constante a lo largo de toda la historia del mundo antiguo y medieval. Ibn Jordahbeh escribió en fecha tan temprana como el siglo IX que era a través del Mediterráneo occidental por donde se transportaban los esclavos de origen eslavo, romano, franco y lombardo (y recalca especialmente que fue una fuente de las esclavas romanas y españolas) (43). El Mar Mediterráneo, el Mare Nostrum así llamado por los romanos, ha permitido siempre a las distintas civilizaciones y culturas que pueblan la zona el relacionarse unas con otras.

En el siglo $X V$, grandes y pequeñas cantidades de esclavos cruzaron el Mar Mediterráneo. Algunos grupos eran enviados de Costantinopla a Venecia, Creta, Sicilia, y a lugares tan distantes como Mallorca y Cataluña. Por un registro del año 1438 descubrimos que Ser Zuan Mozenigo poseía una inversión de 150 esclavos; Ser Alesandro Zen de 19 esclavos; y Ser Giacomo Bader de 13 esclavos. En 1455 Marino Cigalla arribó a Quíos con 114 esclavos de la península de Crimea. De nuevo, un barco fue cargado con 75 esclavos en el año 1455 en Rodas a cuenta de un mercader catalán (44). Durante los siglos XIV y XV la participación catalana en el tráfico del Mediterráneo oriental aumentaría considerablemente. Como ha apuntado Eliyahu Ashtor, los ca-

of Slavery in Medieval Italian Colonies" en The Beginnings of Modern Colonization, Eleven Essays with an intraduction (Ithaca 1970). El más extenso estudio documental sobre la esclavitud del siglo XV en Génova es el de Doménico Gioffre, II mercato degli schiavi a Genova nel secolo XV (Génova 1971); véase asimismo Bariša Krekiš, "Contributo allo studio degli schiavi levantini e balcanici a Venezia (1388-1398) studi in memoria de Federigo Melis, 5 vols. (Nápoles 1978), II: pp. $379-394$

(42) Ion Jaldün (trad, ing. FRANZ ROSENTHAL), The Muqaddimah, An tatroduction to History, 3 vols. (Princeton 1967), vol. II, cap. $V$, sección 8

(43) CHARLES-EMMANUEL DUFOURCO, L'Espagne catalane et le Maghrib aux XIIe et XIVe sièctes (Paris 1966), pp. $71-82$ LOPEZ, p. 30

(44) CHARLES VERLINDEN, "Medieval "Slavers"' en David Herlihy, et al. Economy, Society, and Government in Medieval Italy, Essays in Memory of Robet L. Reynolds !Kent, Ohio 1969), pp. 1, 2, 6, 7. 
talanes fueron unos socios muy activos en el comercio con el Levante musulmán. Descubrimos sin sorprendernos que los mismos embajadores enviados por los reyes de Aragón eran igualmente mercaderes, de tal modo que las embajadas eran misiones comerciales tanto como diplomáticas. La mayoría de los barcos salían de Barcelona, pero también participaban galeras y mercantes de Valencia, Perpignan, Mallorca, Tortosa, y otras ciudades de la Corona de Aragón. Así a principios del siglo XV, de dos a cuatro barcos catalanes llegaban anualmente a los puertos de Egipto y Siria. De 1422 a 1433 , este número aumentó de cinco a siete barcos; de 1435 a 1444 hay un grave descenso a unos dos o tres barcos; y después de 1445, el número de navíos que atracaban anualmente en los puertos levantinos subió a cuatro o cinco (45). Estos contactos comerciales con el norte de África, el Mediterráneo oriental, así como el sur de Francia y las ciudades italianas ilustran cómo se desplazaba la población esclava a través de todo el Mediterráneo. El fenómeno de la esclavitud debe situarse dentro del contexto más amplio que constituye el mundo mediterráneo, y podemos contemplar la esclavitud bajo este punto de vista como otra intersección en la perenne lucha entre los mundos cristiano y musulmán.

¿Cuál era la actitud hacia los musulmanes en Valencia? No podemos decirlo con completa seguridad, pero la literatura sugiere que no hubo un gran afecto entre los distintos grupos: El prejuicio existió entonces tal como existe en el mundo actual. Un ejemplo en el que puede verse la actitud hacia judíos y musulmanes se encuentra en la obra de Francesc Eiximenis, que reflejó los perjuicios populares del pueblo llano cristiano de la época (46). El peor vicio que se asocia a los judíos es la avaricia, mientras que el principal vicio de los musulmanes era su lascivia. A los musulmanes se les consideraba más indeseables incluso que los judíos, sin duda alguna porque el Islam planteaba una verdadera amenaza militar a los cristianos de España. En su Regiment de la cosa publica se queja amargamente de los excesivos rasgos morunos de la ciudad de Valencia. Finalmente, en el Tirant lo blanc - el único romance de caballerías escrito en dialecto valenciano - encontramos un episodio en África donde Tirant se encuentra con un fraile de Valencia que ha venido a rescatar cautivos cristianos. Tras escuchar alabanzas cantadas a las virtudes de la ciudad, se nos informa:

En el futuro, la maldad de sus habitantes será la causa de la ruina de aquella noble ciudad. Será poblada por naciones de mala estirpe, por hombres que se habrán mezclado, y la descendencia resultante será tan malvada que no confiará el hijo en el padre, ni el padre en el hijo, ni el hermano en el hermano. Tres azotes habrá de soportar la noble ciudad según Elías: el primero el de los judíos; el segundo el de los moros; el tercero el de los moros conversos. Serán la causa de una gran destrucción... (47).

\footnotetext{
45) ELIYAHU ASHTOR, Levamt Trade in the Later Middle Ages (Princeton 1983), pp. 35, 337, 339.

(46) DAVID J. VIERA, "The Treatment of the Jew and the Moor in the Catalan Works of Francesc Eiximenis", Revista canadiense de estudios hispánicos 9 (1985), pp. 203-213

(47) JOANOT MARTORELLIMARTÍ JOAN DE GALBA led. de Martín de Riquerl Tirant lo blanc $i$ altres escrits de Joan Martorell (Barcelona 1969), cap. 330: “Aquesta noble ciutat vendrà per temps en gran decaïment per la molta maldat qui en los habitafors d'aquella serà. D'aço serà causa com serà poblada de moltes nacions de gents, que com se seran mesclats, la llavor que eixirà serà tan malvada que lo fill no fiarà del pare, ni lo pare del fill, ni lo germà dẹl germà. Tres cogoixes ha de sostenir aquella noble ciutat, segons recita Elies: la primera de jueus, la segona de moros, la terça de crestians qui no vénen natura, qui per causa d'ells rebrà gran dan e destrucciom.
} 
A principios del siglo $X X$ todavía se utilizaba la figura del moro para infundir miedo a los niños desobedientes.

Las culturas son como grandes rocas, tanto unas como otras están sujetas a la erosión. La población musulmana, los numerosos mudéjares así como los esclavos importados, continuaron existiendo en el Reino de Valencia a lo largo del siglo XV (48). Quizá los esclavos musulmanes ayudaron a inculcar una nueva vitalidad en la comunidad islámica valenciana. Los musulmanes de Valencia vivían en sus propias comunidades, observando sus propias leyes. En disputas sobre los derechos del agua o cuando la ley introducida por los cristianos no trataba una cuestión, siempre podían recurrir al precedente, a la manera en que se hacían las cosas "en los tiempos de los moros" (temps de moros, temps de sarrahins) (49). Las comunidades musulmana, cristiana y judía convivieron unas con otras en un modus vivendi. Esto cambiaría trágicamente en el transcurso del siglo XVI.

(Traducido del inglés por Ovidio Carbonell).

\section{APÉNDICE}

Archivo del Reino de Valencia, Maestre Racional, Reg. 41 (1421), folio 92.

Item pos en reebuda los quals a xxii dies de Octobre del dit any mccccxxi reebe per mi lo dit en Daniel Barcelo d'en Johan de Cordova patro de un leny de xii banchs dela ciutat de Cartagenia a per lo dret al senyor Rey pertanyent de quarte moros que li ajutgi de bona guerra e los quals reebe per mans $\mathrm{d}^{\prime}$ en Miralles nom de deu com per tant me aujngues ab aquell.

folio $94 \mathrm{rv}$.

Item a vii de ffebrer del dit any mccccxxi foren reebuts d'en Marti Andres per dret de passatge de barqua moro cativa de linatge de negres per trametre de juira.

Item a xxviiii de Marc del dit any foren reebuts d'en Johan Bertran per dret de passatge de tres sclavs coes llurs de Moxca Macot e Rastatla de linatge de negres moros per passar aquells a Barcelona.

Item a xviiii de Marc del dit any foren reebuts d'en Domingo d'Arago per dret de passatge de Macot moro de linatge de negres per trametre a Barcelona.

\footnotetext{
(48) Sobre el siglo XV véase a LEOPOLDO PILES ROS, "La sítuación social de las moros de realengo en la Valencia del siglo XV", en Estudios de historia social de España 1 (1949), pp. 225-274; el ensayo bibliográfico de MIGUEL GUAL CAMARENA, uLos Mudéjares valencianos en la época del Magnánimon, IV CHCA, 3 vols. (Pałma de Mallorca 1959-1976). 1: pp. 467-494; MANUEL RUZAFA GARCIA, "Los Mudéjares valencianos en el siglo XV. Una bibliografía", Acta del Simposio de Mudejarismo (Teruel 1986). pp. 291-303; y la sintesis general de MARIA DEL CARMEN BARCELO TORRES, Minorias islámicas en el País Valenciano, historia y dialecto (Valencia 1984).

(49) Véase THOMAS F. GLICK, Irrigation and Society in Medieval Valencia (Cambridge, Mass. 1970)
} 
Item a quatre de Juny del dit any foren reebuts d'en Jacme bertran per dret de passatge de Abrafim moro sclav per anar a Barcelona.

Item lo primer dia de Juliol del dit any foren reebuts d'en Bernat Fenoll fuster per dret de passatge de Mahomat Abenamor moro cativ del dit en $\mathrm{Fe}-$ noll per passar a Barcelona.

Item a quatre du Juliol de dit any mccccxxi foren reebuts d'en Ramon dela Marca per dret de passatge de Ali Abencares moro sclav.

Item a $x$ del propi dit mes forens reebuts d'en Johan Clapes per dret de passatge de Abdalla moro cativ.

Item a xxv de Agost foren d'en Ramon dela Marcha flaquer per dret de passatge de Azmet ben sir moro sclav per trametre a Barcelona.

Item a ii de Decembre del dit any foren rebuts d'en Martia Andres per dret de passatge de barqua mora cativa de linatge de negres per anar a Barcelona.

Item a tres de Decembre foren reebuts d'en Bernat Busquet per dret de passatge de Aballa moro sclav per passar a Mallorca.

Item a xxiii de Octobre del dit any foren reebuts d'en Ramon dela Marcha per dret de passatge de ii cativs de liuzmen e yakie per passatge a Barcelona. 